\title{
Erratum to: School Inspectors as Policy Implementers: Influences and Activities
}

\author{
Jacqueline Baxter $(1)$
}

\section{Erratum to:}

Chapter 1 in: J. Baxter (ed.), School Inspectors, Accountability and Educational Improvement, https://doi.org/10.1007/978-3-319-52536-5_1

In the original version of the book, the country name "Finland" has to be changed to "Belgium" in the abstract of Chapter 1. The erratum chapter and the book have been updated with the change. 